\title{
Whole-grain wheat breakfast cereal has a prebiotic effect on the human gut microbiota: a double-blind, placebo-controlled, crossover study
}

\author{
Adele Costabile ${ }^{1 *}$, Annett Klinder ${ }^{1}$, Francesca Fava ${ }^{1}$, Aurora Napolitano ${ }^{2}$, Vincenzo Fogliano ${ }^{2}$, \\ Clare Leonard $^{3}$, Glenn R. Gibson ${ }^{1}$ and Kieran M. Tuohy ${ }^{1}$ \\ ${ }^{1}$ Department of Food Biosciences, The School of Chemistry, Food Biosciences, and Pharmacy, University of Reading, \\ Reading RG6 6AP UK \\ ${ }^{2}$ Dipartimento di Scienza degli Alimenti, Università di Napoli, 'Federico II' Parco Gussone-Ed.84, Portici, NA 80055, Italy \\ ${ }^{3}$ CPUK, Albany Place, Welwyn Garden City, Herts AL7 IRR UK
}

(Received 31 January 2007 - Revised 21 May 2007 - Accepted 6 June 2007)

Epidemiological studies have shown an inverse association between dietary intake of whole grains and the risk of chronic disease. This may be related to the ability to mediate a prebiotic modulation of gut microbiota. However, no studies have been conducted on the microbiota modulatory capability of whole-grain (WG) cereals. In the present study, the impact of WG wheat on the human intestinal microbiota compared to wheat bran (WB) was determined. A double-blind, randomised, crossover study was carried out in thirty-one volunteers who were randomised into two groups and consumed daily $48 \mathrm{~g}$ breakfast cereals, either WG or WB, in two 3-week study periods, separated by a 2-week washout period. Numbers of faecal bifidobacteria and lactobacilli (the target genera for prebiotic intake), were significantly higher upon WG ingestion compared with WB. Ingestion of both breakfast cereals resulted in a significant increase in ferulic acid concentrations in blood but no discernible difference in faeces or urine. No significant differences in faecal SCFA, fasting blood glucose, insulin, total cholesterol (TC), TAG or HDL-cholesterol were observed upon ingestion of WG compared with WB. However, a significant reduction in TC was observed in volunteers in the top quartile of TC concentrations upon ingestion of either cereal. No adverse intestinal symptoms were reported and WB ingestion increased stool frequency. Daily consumption of WG wheat exerted a pronounced prebiotic effect on the human gut microbiota composition. This prebiotic activity may contribute towards the beneficial physiological effects of WG wheat.

Whole-grain wheat: Gut microbiota: Prebiotic: Gastrointestinal health: Ferulic acid: Cholesterol

Whole-grain (WG) intake is associated with beneficial health effects and epidemiological studies have shown that it is protective against cancer, diabetes, obesity and in particular $\mathrm{CVD}^{1-3}$. Whole grains are rich in fermentable carbohydrates such as dietary fibre, resistant starch and oligosaccharides and one proposed protective mechanism is the effect on human gut microbiota ${ }^{4}$. Diet-microbe interactions within the colon are now thought to play important roles in regulating mucosal physiology and may provide protection from invading pathogens, impact on liver function, bone health, satiety and chronic diseases such as some cancers, inflammatory conditions and heart disease ${ }^{5,6}$. Many of these health-promoting activities are likely to be mediated by dominant members of the gut microbiota which have co-evolved with the human colon. Bacteria now seen as beneficial for human health include species belonging to the genera Bifidobacterium and Lactobacillus $^{7}$. Similarly, maintenance of stable and diverse populations of commensal bacteria e.g. Eubacterium spp., Atopobium spp., and certain Bacteroides spp., characterises the gut microbiota in health and no doubt contributes greatly towards improved colonisation resistance and protection against gastrointestinal disorder ${ }^{8}$. Functional foods targeting the human colon aim to stimulate beneficial genera either directly by providing growth substrates which selectively promote the growth of an individual's autochthonous bifidobacteria and lactobacilli in vivo within the colon (prebiotics) or indirectly by introducing live exogenous bacteria in specially formulated foods (probiotics). Prebiotics are generally non-digestible soluble fibres such as inulin, oligofructose or galactooligosaccharides, and mimic the bifidogenic activities of non-digestible oligosaccharides present in human breast milk ${ }^{9}$. There is a growing body of evidence that certain prebiotics may mediate important health effects such as improved mineral absorption ${ }^{10}$, lowering of blood TAG concentrations in the hyperlipidaemic ${ }^{11}$ and affecting colon cancer risk by reducing faecal water genotoxicity ${ }^{12,13}$ and in animal studies, reducing the number and size of chemically induced colonic tumours ${ }^{14}$. Currently, no information exists on the prebiotic potential of WG wheat.

WG cereals comprise three distinct physiological regions, the endosperm, germ and bran. The grain endosperm is composed mainly of starch, whose digestibility and subsequent

Abbreviations: WB, wheat bran; WG, whole-grain; TC, total cholesterol.

* Corresponding author: Dr A. Costabile, fax +44 (0)118931 0080, email a.costabile@reading.ac.uk 
fermentability will be affected by food processing (e.g. heating, drying, acid/enzymatic digestion). Grain germ, which is a minor fraction of the grain in wheat, is made up of a complex mixture of lipids, proteins and some mainly soluble carbohydrates, while wheat bran (WB) is composed of nondigestible, mainly insoluble and poorly fermented carbohydrates such as cellulose, hemicellulose, arabinoxylan as well as polyphenolic lignins all together indicated as dietary fibre. Whole grains contain many compounds such as antioxidants, lignans, vitamins and minerals that may protect against chronic disease. Particularly in cereal products, dietary fibre is composed of different compounds that may be coresponsible for many of its physiological effects. An important amount of phenolic compounds $(500-1500 \mathrm{mg} / \mathrm{kg}$ ), mainly ferulic acid, is linked to the dietary fibre and this may explain why wheat dietary fibre has a marked antioxidant activity ${ }^{15}$. Dietary fibre in toto (carbohydrate and phenolic compounds) mediates their biological activity on host health through the colonic microbiota $^{16,17}$. There is currently no information on the impact of specific WG cereals on the microbial ecology of the human colon, and how this may impact upon chronic disease risk.

In the present study, the efficacy of WG wheat compared with WB alone to beneficially modulate the gastrointestinal microbiota and their activities was determined. The objective was to assess the ability of WG compared with WB to selectively increase numbers of bifidobacteria and alter colonic metabolic output. The secondary objective was to determine the relative impact of $\mathrm{WG}$ and $\mathrm{WB}$ on biomarkers of gut health (bowel habit and faecal water genotoxicity) and blood lipid parameters. We present the findings of a double-blind, placebo-controlled crossover study where thirty-one healthy subjects were randomised in two groups and were fed either WG wheat breakfast cereal $(48 \mathrm{~g} / \mathrm{d})$, or WB breakfast cereal $(48 \mathrm{~g} / \mathrm{d})$ as placebo for 3 weeks. After a 2-week wash-out phase volunteers were then crossed over to the other breakfast cereal treatment for another 3 weeks. Fasting blood, $24 \mathrm{~h}$ urine and single stool samples were collected before and after treatment with the cereals, and changes within the gut microbiota and its metabolic output in terms of SCFA profiles and plasma ferulic acid.

\section{Material and methods}

\section{Subjects}

Thirty-two healthy volunteers (20-42 years of age, average age of 25 years; sixteen females, fifteen males) were recruited from the Reading area. Written consent was obtained from each person and selection took place following determination of health status through a medical interview and adherence to the inclusion/exclusion criteria. The subjects all satisfied the following inclusion criteria: they were all between 18 and 50 years old with a BMI between 20 and $30 \mathrm{~kg} / \mathrm{m}^{2}$. Good general health was determined by medical questionnaire. Volunteers were excluded from the trial if there was evidence of physical or mental disease or major surgery as revealed by history or physical examination, which might limit participation in or completion of the study. Volunteers with a history of drug abuse, including alcohol, and smokers were excluded. Volunteers could not be pregnant, lactating or planning pregnancy, have severe allergy or a history of severe abnormal drug reaction. Intake of an experimental drug within 4 weeks prior to study, former participation in prebiotics or laxative trial within the previous 3 months, use of antibiotics within the previous 6 months, chronic constipation, diarrhoea or other chronic gastrointestinal complaint (e.g. irritable bowel syndrome) and intake of other specific prebiotics or probiotics, drugs active on gastrointestinal motility, or a laxative of any class for 4 weeks prior to study, were all prohibited. The study was approved by the Ethics Committee of the University of Reading.

\section{Requirements for diet and medication during study}

The intake of the following foods or substances was not permitted: confirmed prebiotics (such as oligosaccharides e.g. fructooligosaccharide or inulin), probiotics (e.g. live yoghurts, fermented milk drinks), high bran or WG breakfast cereals other than the test food, drugs active on gastrointestinal motility, antibiotic treatment or any class of laxative. Any medication taken was recorded in diaries. Volunteers were instructed not to alter their usual diet or fluid intake during the trial periods.

\section{Study design}

The dietary intervention study was performed as a doubleblind, randomised, placebo-controlled crossover manner. Thirty-two healthy volunteers were recruited onto the study but one volunteer dropped out due to personal reasons ( $n$ 31 ). For a 2 -week period prior to dietary intervention, volunteers followed a restricted diet as described earlier. Thirty-one subjects were randomly allocated into one of two groups. One group ( $n$ 16) consumed first the $100 \%$ WG wheat breakfast cereal $(48 \mathrm{~g} / \mathrm{d})$ for 3 weeks, and then after a 2-week washout period, they consumed the equivalent placebo (WB based breakfast cereal; $48 \mathrm{~g} / \mathrm{d}$ ) for 3 weeks. The other group ( $n$ 15) received first the equivalent placebo (WB based breakfast cereal; $48 \mathrm{~g} / \mathrm{d}$ ) for 3 weeks, and then after a 2-week washout, they consumed the $100 \%$ WG wheat breakfast cereal $(48 \mathrm{~g} / \mathrm{d})$ for another 3 -week treatment period. Each product was given for 3 weeks, followed by 2 -week wash-out periods during which no breakfast cereal was consumed (Fig. 1). All test materials were packaged, labelled and randomised by the Cereal Partners UK (Welwyn Garden City, Herts., UK) prior to the study, investigators were not aware of which of the treatments the volunteers were taking and the volunteers were unaware which of the two breakfast cereals they were given (WG or WB).

Volunteers were asked to keep diaries while ingesting cereals, to record stool frequency and consistency (constipation, hard, formed, soft or diarrhoea), abdominal pain (none, mild, moderate or severe), intestinal bloating (none, mild, moderate or severe) and flatulence (none, mild, moderate or severe) on a daily basis. Any concomitant medication and adverse events were recorded.

Faecal samples, $24 \mathrm{~h}$ urine and $30 \mathrm{ml}$ fasting venous blood were collected from each volunteer at five different time points before and after each treatment arm and $14 \mathrm{~d}$ after the second treatment arm within $48 \mathrm{~h}$ (i.e. $0,21,36,58,73 \mathrm{~d}$ ). 
RD Treatment 1 WO1 Treatment 2 WO2
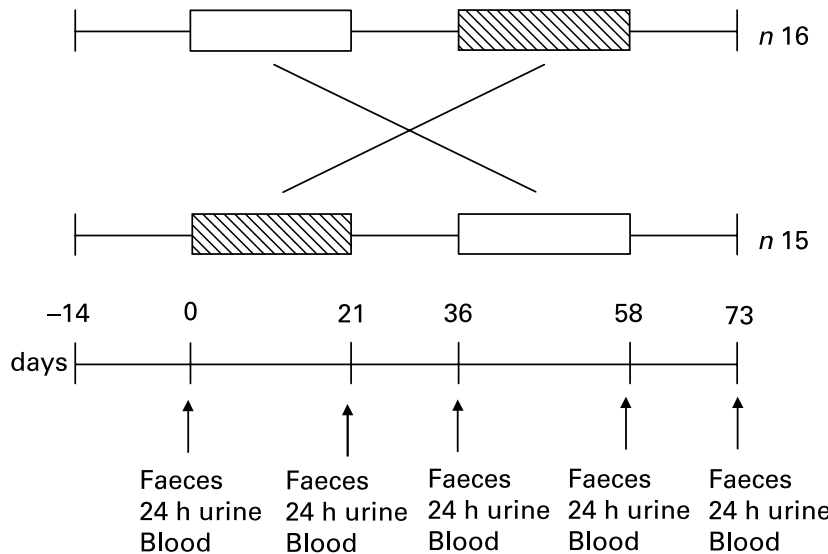

Fig. 1. Study design of a double-blind randomised placebo-controlled parallel study in which thirty-one subjects received WG $(\square)$ and WB $(\mathbb{\mathbb { N }})$ for a period of 3 weeks each. One product was given over the first 3 -week period followed by a 2-week washout period (WO), and then volunteers received the second product during the next 3 weeks, followed by a further 2-week washout period. A 2-week restriction diet (RD) preceded the start the trial. Faecal samples, $24 \mathrm{~h}$ urine and blood were collected from each volunteer at five different time points before and after each treatment and $14 \mathrm{~d}$ after the second treatment within $48 \mathrm{~h}$ (i.e. $0,21,36,58,73 \mathrm{~d}$ ).

\section{Composition of breakfast cereals}

The energy intake of the cereals was not the same with WB containing $1184 \mathrm{~kJ} / 100 \mathrm{~g}$ and WG containing $1442 \mathrm{~kJ} / 100 \mathrm{~g}$ cereal, respectively. WG contained (per $100 \mathrm{~g}$ ) $67.8 \mathrm{~g}$ carbohydrates, of which there are $0.9 \mathrm{~g}$ sugars; $11.6 \mathrm{~g}$ protein, $2.5 \mathrm{~g}$ fat and $11.8 \mathrm{~g}$ fibre. WB contained $48 \mathrm{~g}$ carbohydrate/ $100 \mathrm{~g}$ which was considerably lower than in WG; however, the proportion of sugars in the WB was higher at $17 \mathrm{~g} / 100 \mathrm{~g}$. The remaining $31 \mathrm{~g}$ carbohydrate in WB was starch. WB contained a considerably higher amount of fibre $(27 \mathrm{~g} / 100 \mathrm{~g})$. The protein and fat content of WB were similar to those of WG, at $14 \mathrm{~g}$ and $3.5 \mathrm{~g}$, respectively per $100 \mathrm{~g}$.

\section{Enumeration of faecal microbial populations by fluorescence} in situ hybridisation

Faecal samples were stored in an anaerobic cabinet $\left(10 \% \mathrm{H}_{2}\right.$; $10 \% \mathrm{CO}_{2} ; 80 \% \mathrm{~N}_{2}$ ) for no longer than $2 \mathrm{~h}$ prior to processing. The enumeration of faecal microbial populations was carried out using fluorescently labelled 16S rRNA targeted oligonucleotide probes and fluorescence in situ hybridisation ${ }^{18}$. Oligonucleotide probes (MWG-Biotech, Milton Keynes, UK) targeting the Atopobium group ( $5^{\prime}$-GGT CGG TCT CTC $\mathrm{AAC}$ CC) ${ }^{19}$,

Bacteroides spp. (5'-CCA ATG TGG GGG ACC TT $)^{20}$, Bifidobacterium spp. (5'-CATCCGGCATTACCACCC $)^{21}$, Eubacterium rectale group (5'-GCTTCTTAGTCARGT$\mathrm{ACCG})^{22}$, Clostridium histolyticum group (5'-TTATGCGGTATTAATCTYCCTTT) ${ }^{22}$ and the lactobacilli/enterococci $\left(5^{\prime} \text {-GGTATTAGCAYCTGTTTCCA }\right)^{23}$ were used for enumeration of dominant members of the gut microbiota. The probes were labelled at the $5^{\prime}$ end with the fluorescent dye Cy3. For the enumeration of total cells, samples were stained with the nucleic acid stain 4',6'-diamino-2-phenylindole (DAPI). Slides were enumerated using a Nikon microscope with an
EPI-fluorescence attachment (Nikon UK, Kingston-uponThames, UK).

\section{SCFA analysis}

Aliquots $(1 \mathrm{ml})$ of $100 \mathrm{~g} / \mathrm{l}$ faecal suspension in sterile $1 \mathrm{M}$ PBS, $\mathrm{pH} 7.0$, were dispensed into $1.5 \mathrm{ml}$ tubes and centrifuged at $13000 \mathrm{~g}$ for $5 \mathrm{~min}$ to pellet bacteria and other solids. Supernatants were then filtered using a $0.2 \mu \mathrm{m}$ polycarbonate syringe filter and added to four volumes of acetonitrile containing $3.7 \mathrm{~mm}$ 2-ethylbutyric acid as the internal standard. Calibration was done using standard solutions of acetic acid, propionic acid, i-butyric acid, n-butyric acid, i-valeric acid, $\mathrm{n}$-valeric acid, n-caproic acid in acetonitrile. Standard solutions containing $20 \mathrm{~mm}, 10 \mathrm{~mm}, 5 \mathrm{~mm}, 1 \mathrm{~mm}$ and $0.5 \mathrm{~mm}$ of each external standard were used. Fatty acids were determined by GLC using a Hewlett Packard (Agilent) 5890 Series II GC system (HP, Crawley, West Sussex, UK) fitted with a Permabond FFAP column $(25 \mathrm{~m} \times 0.32 \mathrm{~mm}$; Macherey-Nagel, Düren, Germany) and a flame-ionisation detector. The carrier gas, He, was delivered at a flow rate of $2.0 \mathrm{ml} / \mathrm{min}$. The head pressure was set at 0.862 bar and the split ratio was 25:1. Injector, column, and detector were set at $220^{\circ} \mathrm{C}, 140^{\circ} \mathrm{C}$ (isothermic), and $220^{\circ} \mathrm{C}$, respectively. After $5 \mathrm{~min}$ the column temperature was increased at $20^{\circ} \mathrm{C} / \mathrm{min}$ increments to run for a further $15 \mathrm{~min}$. Peaks were integrated using Atlas Lab managing software (Thermo Lab Systems, Mainz, Germany). SCFA concentrations were calculated by comparing their peak areas with those of the standards.

Faecal samples, plasma and $24 \mathrm{~h}$ urine preparation for $L C-$ MS/MS analysis

Faecal sample preparation was carried out in conditions according to a procedure published by Kroon et al. ${ }^{24}$ with some modifications. Briefly, faecal samples $(500 \mu \mathrm{l})$ were treated for $2 \mathrm{~h}$ in the dark with $2 \mathrm{M} \mathrm{NaOH}$ at $35^{\circ} \mathrm{C}$. The solutions were acidified to $\mathrm{pH} 2.0$ with $4 \mathrm{M} \mathrm{HCl}$. Phenolic acids were extracted twice with ethyl acetate $(10 \mathrm{ml})$ under agitation and $5 \mathrm{~min}$ centrifugation at $4000 \mathrm{~g}$. The ether phases were collected in amber test tubes and completely evaporated under $\mathrm{N}_{2}$. The dry extracts were dissolved in $1 \mathrm{ml} 50 \%$ aqueous methanol and filtered (PTFE membrane, $0.45 \mu \mathrm{m}$ Millipore, Bedford, USA). A $20 \mu \mathrm{l}$ aliquot of the filtrate was then analysed by LC-MS/MS. Plasma samples $(500 \mu \mathrm{l})$ were spiked with $0.5 \mu \mathrm{g} o$-coumaric acid as internal standard. Following acidification ( $\mathrm{pH} 6.5,0.5 \mathrm{M} \mathrm{HCl}$ ), plasma samples were incubated with $\beta$-glucuronidase $\left(7.5 \times 10^{4}\right.$ units/l) and sulfatase $\left(1.5 \times 10^{4}\right.$ units/l) for $1 \mathrm{~h}$ at $37^{\circ} \mathrm{C}$ in a shaking water bath. This mixture was further acidified with $\mathrm{HCl}$ to $\mathrm{pH}<2$ and then extracted with ethyl acetate $(3 \times 3 \mathrm{ml})$, and the organic phase rotary evaporated to dryness. The residue was dissolved in $500 \mu \mathrm{l} 50 \%$ methanol, centrifuged for $5 \mathrm{~min}$ at $15000 \mathrm{~g}$, and filtered through a $0.45 \mu \mathrm{m}$ syringe filter prior to analysis by LC-MS. For the collection of urine for the study, volunteers were provided with a $24 \mathrm{~h}$-urine container (Fisher Scientific Ltd, Loughborough, Leicestershire, UK) containing $2 \mathrm{~g}$ ascorbic acid. The total volume of urine was recorded after which the urine samples were dispensed into $1.5 \mathrm{ml}$ microcentrifuge tubes and frozen at $-20^{\circ} \mathrm{C}$. The urine samples solution $(2 \mathrm{ml})$ were mixed with $450 \mu \mathrm{l} 50 \mathrm{M}$ sodium acetate buffer 
(pH 5.5) and $1000 \mu \mathrm{l} 0.6 \mathrm{M} \mathrm{CaCl}_{2}$ solution. These solutions were incubated in a manner similar to that of the plasma samples, followed by an acidification step with $20 \mu \mathrm{l} 6 \mathrm{M}$ $\mathrm{HCl}$ solution. Then the urine was extracted twice with $4 \mathrm{ml}$ ethyl acetate and the organic phase was rotary evaporated to dryness. The samples were dissolved in $500 \mu \mathrm{l} 50 \%$ methanol, centrifuged for $5 \mathrm{~min}$ at $15000 \mathrm{~g}$, and filtered through a $0.45 \mu \mathrm{m}$ syringe filter prior to LC-MS/MS analysis.

\section{HPLC-ESI-MS/MS analysis}

HPLC-ESI-MS/MS analyses were carried out on a LC-MS/ MS System (API 3000, MDS SCIEX). LC analyses were performed using a system consisted of a series 200 binary pump (Perkin Elmer, USA). The mass spectrometer was equipped with a Model 11 syringe pump (Harvard, Apparatus, Holliston, MA, USA). A turbo Ionspray source, with the nebuliser temperature set at $450^{\circ} \mathrm{C}$, was used. The collision-induced dissociation was carried out using $\mathrm{N}_{2}$ as collision gas. Analyses were performed using a Prodigy column $5 \mu$ ODS3 100A, $250 \times 4.60 \mathrm{~mm}$ (Phenomenex, USA). The solvent system was water $(0.1 \%)$, formic acid (solvent A) and methanol (solvent B); only in urine analyses solvent $\mathrm{B}$ was acetonitrile. The linear solvent gradient was as follows: $0-10 \min 95 \%$ A $5 \%$ $\mathrm{B}, 10-12 \min 55 \%$ A $45 \% \mathrm{~B}, 12-15 \min 45 \%$ A $55 \% \mathrm{~B}$, $15-17 \min 0 \%$ A $100 \%$ B, $17-22 \min 0 \%$ A $100 \%$ B, $22-24 \min 95 \%$ A $5 \%$ B returned to initial conditions. The acquisition was carried out by a multiple reaction monitoring system, in negative mode, monitoring the transition of parent and product ions specific for each compound with a dwell time of $500 \mathrm{~ms}$. Thirteen phenylacetic, phenylpropionic and cinnamic acid derivates, were simultaneously detected (see Table 1). To promote ionisation of the precursor ion, the volt age applied was 4500 while the collision energy and collision cell exit potential was optimised for each transition.

Data acquisition and processing were performed using Analyst software 1.4. The amount of hydroxycinnamates compounds was expressed in $\mu \mathrm{g} / \mathrm{l}$.

\section{Faecal water preparation}

Faecal samples were diluted 1:2 (w/v) in $1 \mathrm{~m}$ ice-cold PBS $(1 \mathrm{~g}$ faeces plus $1 \mathrm{ml}$ PBS) in a stomacher bag. Samples were homogenised in a stomacher for $2 \mathrm{~min}$ at high speed or until a uniform consistency was achieved. Aliquots $(10 \mathrm{ml})$, in duplicate for each sample, were then transferred into ultracentrifuge tubes (Beckman Ultra-clear tubes, Beckman Ltd, High Wycombe, Bucks., UK) and the tubes stored at $-70^{\circ} \mathrm{C}$. Samples were defrosted on ice prior to centrifugation, then ultracentrifuged at $64000 \mathrm{~g}$ for $2 \mathrm{~h}$ at $4^{\circ} \mathrm{C}$ (Beckman Optima L90K Ultracentrifuge). Following centrifugation the tubes were placed on ice and the supernatants (faecal water) were carefully removed and placed into $7 \mathrm{ml}$ Sterilin tubes. The faecal waters were then filtered through a $0.2 \mu \mathrm{m}$ syringe filter, dispensed into $0.5 \mathrm{ml}$ aliquots and frozen at $-70^{\circ} \mathrm{C}$ and used for single cell gel electrophoresis.

\section{Treatment of HT29 cells}

The human colon carcinoma cell line HT29 was maintained in Dulbecco's modified Eagle medium (DMEM) supplemented with $10 \%$ fetal bovine serum and penicillin $(50 \mathrm{IU} / \mathrm{ml}) / \mathrm{strep}-$ tomycin $(50 \mu \mathrm{g} / \mathrm{ml})$ in a humidified $5 \% \mathrm{CO}_{2}$ incubator at $37^{\circ} \mathrm{C}$. Prior to incubation with faecal water, HT29 cells were harvested and adjusted to a concentration of $3.2 \times 10^{6}$ cells/ $\mathrm{ml}$ in un-supplemented DMEM. In order to determine faecal water genotoxicity, faecal water was added to the cell suspension giving a final concentration of $30 \%$ faecal water and $2 \times 10^{6}$ cells $/ \mathrm{ml}$. Then cell suspensions were incubated for $30 \mathrm{~min}$ at $37^{\circ} \mathrm{C}$. $30 \%$ PBS served as a negative control.

\section{Determination of DNA damage (Comet assay)}

Numbers and viabilities of the treated cells were determined with Trypan Blue (Sigma-Aldrich) in aliquots. Briefly, following incubation with faecal water, $20 \mu l$ cell suspension was mixed with $20 \mu \mathrm{l}$ Trypan Blue and counted under a light microscope using a Neubauer hemacytometer. Evenly blue stained cells were identified as dead cells while round, shiny cells were counted as viable cells. Viability is expressed as percentage of viable cells compared to the total cell count. The remaining suspensions were centrifuged at $200 \mathrm{~g}$ for $5 \mathrm{~min}$ at $4^{\circ} \mathrm{C}$ and the resulting cell pellets were mixed with agarose and distributed onto microscope slides. $\mathrm{H}_{2} \mathrm{O}_{2}$ (obtained as a $30 \%$ aqueous solution from Merck \& Co. Inc., Global Headquarters, USA) was used as genotoxic model

Table 1. Parent ions and ions of phenolic acids monitored in the multiple reaction monitoring mode by HPLC-ESI-MS/MS

\begin{tabular}{lccc}
\hline Compounds & Molecular mass & Parent ions $\left([\mathrm{M}-\mathrm{H}]^{-}, \mathrm{m} / \mathrm{z}\right)$ & Product ions $(\mathrm{m} / \mathrm{z})$ \\
\hline Clorogenic acid & 354 & 353 & 191 \\
Ferulic acid & 194 & 193 & 134 \\
Caffeic acid & 180 & 179 & 135 \\
Vanillic acid & 168 & 167 & 123 \\
Hippuric acid & 179 & 178 & 134 \\
4-Hydroxyhippuric acid & 195 & 194 & 100 \\
p-Coumaric acid & 164 & 163 & 119 \\
3,4-Dihydroxyphenylpropionic acid & 182 & 181 & 59 \\
3-Hydroxyphenylpropionic acid & 166 & 165 & 121 \\
3-Hydroxyphenylacetic acid & 152 & 151 & 107 \\
Homovanillic acid & 182 & 181 & 137 \\
Phenylacetic acid & 136 & 135 & 91 \\
4-Hydroxybenzoic acid & 138 & 137 & 93 \\
\hline
\end{tabular}


substance. Cell suspensions $\left(2 \times 10^{6}\right.$ cells $\left./ \mathrm{ml}\right)$ were incubated with $75 \mu \mathrm{M}$ for $5 \mathrm{~min}$ on ice. Further steps of single cell gel electrophoresis (alkaline version of the 'Comet assay') were carried out as originally described by Singh et al. ${ }^{25}$. In summary, the slides were placed into the lysis solution $\left(100 \mathrm{mM} \mathrm{Na}_{2}\right.$ EDTA,

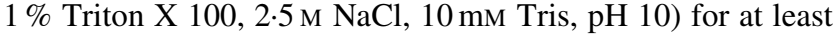
$60 \mathrm{~min}$ at $4^{\circ} \mathrm{C}$ and further processed in the microgel electrophoresis chamber containing alkaline solution $\left(1 \mathrm{mM} \mathrm{Na} \mathrm{N}_{2}\right.$ EDTA, $300 \mathrm{~mm} \mathrm{NaOH}, \mathrm{pH}$ 13). After 20 min incubation for DNA unwinding, electrophoresis was carried out at $1.25 \mathrm{~V} / \mathrm{cm}$ and $300 \mathrm{~mA}$ for $20 \mathrm{~min}$. Slides were then washed with neutralisation buffer (0.4 M Tris, $\mathrm{pH} 7.5)$ and stained with ethidium bromide (Sigma-Aldrich,). The microscopic analysis revealed images of more or less damaged DNA ('comets') ${ }^{26}$. The proportion and extent of DNA migration were used as basis for evaluation. These parameters were quantified using the image analysis system of Komet 5.5 (Kinetic Imaging Ltd.). Fifty DNA spots were evaluated per slide. For each faecal-water sample three gels were processed for determination of DNA strand breaks.

\section{Blood samples collection and analysis}

For each volunteer, blood samples were collected into one $10 \mathrm{ml}$ EDTA tube (BD Vacutainer ${ }^{\circledR}$ EDTA Tube, BD, Cowley, Oxon., UK) for the analysis of fasting TAG, total cholesterol (TC) and HDL-cholesterol concentrations; into one $2 \mathrm{ml}$ fluoride/oxalate tube (BD Vacutainer ${ }^{\circledR}$ Fluoride/Oxalate Tube) for the analysis of fasting glucose concentration and into one $10 \mathrm{ml}$ heparin tube (BD Vacutainer ${ }^{\circledR}$ Plasma Tube) for the analysis of fasting insulin concentration and ferulic acid. Following collection all samples were kept on ice until centrifugation. Plasma samples were recovered by centrifugation at $1700 \mathrm{~g}$ for $10 \mathrm{~min}$, dispensed into $1.5 \mathrm{ml}$ microcentrifuge tubes and frozen at $-20^{\circ} \mathrm{C}$ within $1 \mathrm{~h}$ from the collection. Plasma samples were defrosted and centrifuged for $5 \mathrm{~min}$ at $1500 \mathrm{~g}$ prior to analysis.

Determination of plasma TAG, glucose, total cholesterol and HDL-cholesterol concentration

Plasma TAG, glucose, TC and HDL-cholesterol concentrations were determined using the Monarch Automatic Analyzer ILab 600 (Instrumentation Laboratories Ltd, Cheshire, UK). Test kits (IL Test triacylglycerols, IL Test cholesterol, IL Test HDL cholesterol and IL Test glucose (hexokinase)) supplied by Instrumentation Laboratories were used according to instructions for the determination of plasma TAG, TC, HDL-cholesterol and glucose, respectively. Two quality control samples, Wako Control Serum I and Wako Control Serum II (Alpha Laboratories Ltd, Eastleigh, Hants., UK), containing normal and abnormal known concentration of TAG, TC, HDL-cholesterol and glucose were included at the beginning and at the end of each batch analysis. Sample results were accepted if quality control values were within the range specified by the manufacturers.

\section{Determination of plasma insulin concentration}

The determination of plasma insulin concentration was carried out using a specific commercial ELISA kit (DAKO Diagnostic Ltd, Cambridgeshire, UK). Prior to analysis plasma samples were thawed on a roller mixer. Calibrators and reagents were prepared according to manufacturer's instructions. A $25 \mu \mathrm{l}$ aliquot of plasma, calibrator or control was pipetted onto a 96-well plate and $100 \mu \mathrm{l}$ anti-insulin antibody, horseradish peroxidase, conjugate was added. The plate was shaken for $1 \mathrm{~h}$ at room temperature. Following incubation, the plate was washed three times with wash buffer. A $100 \mu \mathrm{l}$ aliquot of substrate solution was added to each well and the plate shaken for $10 \mathrm{~min}$ at room temperature. The reaction was stopped by addition of $100 \mu \mathrm{l}$ stop solution and the plate read immediately at $450 \mathrm{~nm}$ using an automated ELISA plate spectrophotometer (Tecan GENios; Process Analysis and Automation Ltd, Farnborough, Hants., UK). Insulin concentrations of the samples and quality controls were determined automatically by reading from the standard curve using Magellan (version 5.01) computer software.

\section{Statistical analysis}

All statistical analyses were performed using either generalised linear modelling or one-way ANOVA. Subsequent investigation of the three pairwise comparisons (i.e. baseline $v$. WG, baseline $v$. WB, and WG $v$. WB) used Tukey's post test with significance set at $P<0 \cdot 05$. We used GenStat ${ }^{\circledR}$ for Windows ${ }^{\circledR}$ 8th Edition Released for analysis.

\section{Results}

\section{Faecal bacteriology}

Population levels of the dominant members of the human gut microbiota in thirty-one volunteers were determined using fluorescence in situ hybridisation and are expressed as $\log _{10}$ cells/g faeces (mean value with $\mathrm{SD}, n$ 31).

It was confirmed that there was no carry-over from the first leg of the crossover study by statistical evaluation using a generalised linear model as there were no significant differences regarding the sequence of WB (placebo) or WG (treatment) for all of the tested bacterial groups. Using this statistical analysis we also found highly significant treatment effects for bifidobacteria and lactobacilli $(P<0.001)$ and to a lesser extent for Atopobium spp. $(P=0.024)$ compared with placebo. In order to have a more in-depth analysis and to compare WB and WG to pre-intervention samples (pre-WB or pre-WG) we used one-way ANOVA with Tukey's post test. Pre-WB and pre-WG data are either time point $1(0$ days) or time point 3 (36 days) values depending whether one or the other immediately preceded the respective treatment, WG or WB. The results from this comparison are presented in Table 2.

Numbers of bifidobacteria were significantly higher during the ingestion of the WG compared with the WB treatment period $(P<0 \cdot 001)$. A significant increase in Bifidobacterium spp. numbers was also observed during WG intake compared with pre-WG $(P<0 \cdot 01)$, while no changes were found between pre-WB and WB. Numbers of faecal lactobacilli/ enterococci increased significantly with ingestion of either WB or WG compared with pre-treatment samples. However, the magnitude of change was significantly higher after WG compared with WB intake $(P<0 \cdot 05)$. Numbers of clostridia increased significantly during WB intake compared with 
Table 2. Faecal bacterial numbers for thirty-one volunteers over the trial period. Bacterial counts in stool samples as determined by fluorescence in situ hybridisation are shown expressed as mean $\log _{10}$ cells/g faeces

(Mean values and standard deviations)

\begin{tabular}{|c|c|c|c|c|c|c|c|c|}
\hline \multirow[b]{2}{*}{ Bacterial group } & \multicolumn{2}{|c|}{ Pre-WB } & \multicolumn{2}{|c|}{ WB } & \multicolumn{2}{|c|}{ Pre-WG } & \multicolumn{2}{|c|}{ WG } \\
\hline & Mean & SD & Mean & SD & Mean & SD & Mean & SD \\
\hline Total bacteria & $10 \cdot 7$ & $0 \cdot 1$ & $10 \cdot 7$ & $0 \cdot 1$ & $10 \cdot 8$ & 0.2 & $10 \cdot 8$ & $0 \cdot 1$ \\
\hline Bacteroides spp. & $9 \cdot 6$ & 0.2 & $9 \cdot 6$ & 0.3 & $9 \cdot 6$ & 0.3 & $9 \cdot 7$ & 0.3 \\
\hline Eubacterium rectale group & $10 \cdot 1$ & 0.2 & $10 \cdot 0$ & 0.2 & $10 \cdot 0$ & 0.1 & $10 \cdot 1$ & 0.1 \\
\hline Bifidobacterium spp. & $8 \cdot 9^{a}$ & 0.4 & $8 \cdot 8^{b}$ & 0.4 & $8 \cdot 5^{c}$ & 0.5 & $9 \cdot 3^{a, b, c}$ & 0.4 \\
\hline Atopobium spp. & 8.9 & 0.3 & 8.9 & 0.3 & $9 \cdot 1$ & 0.4 & $9 \cdot 1$ & 0.3 \\
\hline Cl. histolyticum/perfringens gp. & $8 \cdot 2$ & 0.5 & $8.5^{a}$ & 0.4 & $8 \cdot 2^{a}$ & 0.6 & $8 \cdot 4$ & 0.3 \\
\hline Lactobacilli/enterococci & $8 \cdot 0^{\mathrm{a}, \mathrm{b}}$ & 0.4 & $8 \cdot 4^{a, c, d}$ & 0.2 & $8 \cdot 1^{\mathrm{c}, \mathrm{e}}$ & 0.4 & $8 \cdot 7^{b, d}$ & 0.2 \\
\hline
\end{tabular}

WB, wheat bran; WG, whole-grain.

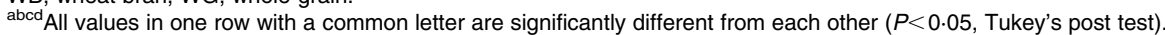

pre-WG $(P<0 \cdot 05)$ but no significant difference was observed in this bacterial group between WG and WB feeding periods. No significant changes in numbers of total bacteria, Bacteroides spp., Atopobium spp. and Eubacterium rectale group were observed.

\section{Colonic metabolic output (ferulic acid and SCFA} concentrations)

Thirteen phenolic acids and their metabolites were quantified by LC-MS/MS in urine and plasma after treatment by $\beta$-glucuronidase and sulfatase. Concentrations of plasma ferulic acid, the main phenolic compounds in wheat, increased upon ingestion of either WG or WB, with higher concentrations found upon ingestion of WB (Fig. 2). The average concentration of plasma ferulic acid increased from $2.28 \mu \mathrm{g} / \mathrm{l}$ at baseline to $5.70 \mu \mathrm{g} / \mathrm{l}$ after WG and $6.22 \mu \mathrm{g} / \mathrm{l}$ after WB consumption, with great variability among subjects. Caffeic acid, 3-hydroxyl-phenylpropionic and hippuric acid were also detected, but at much lower concentrations.

In urine, two main microbiota metabolites of phenolic acids were identified: 3,4-dihydroxyphenylpropionic acid and

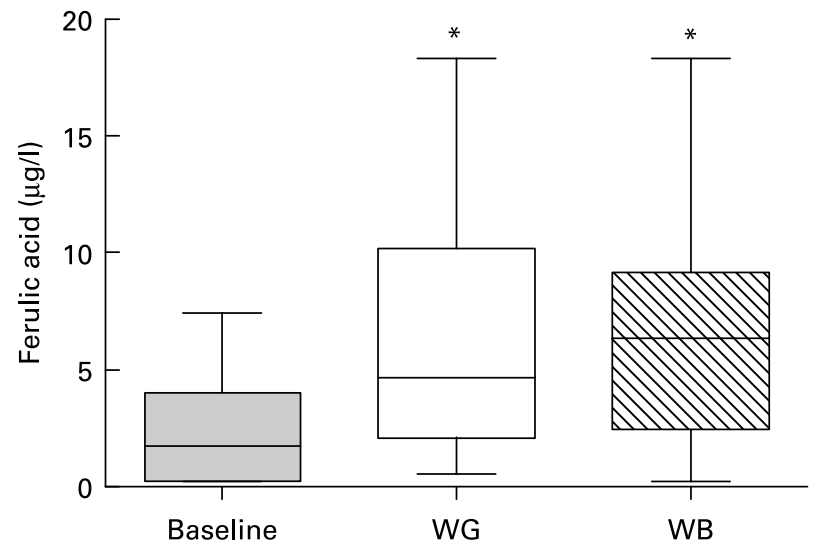

Fig. 2. Ferulic acid concentrations in plasma. There was a significant difference in the concentration of ferulic acid in blood at baseline compared to whole-grain (WG) or wheat bran (WB) treatment periods $\left({ }^{*} P<0.05\right.$; one way ANOVA with Tukey's post test). Data are depicted as box plots with maximum value, 75th percentile (upper line of box), median (middle line of box), 25th percentile (lower line of box) and minimum ( $n 31)$. 4-hydroxybenzoic acid, while other compounds such as caffeic acid and 3-hyrroxyphenilacetic acid, were present at trace concentrations. The concentration of 3,4-dihydroxyphenylpropionic acid tended to increase upon intake of both WG and WB (average value $24.7 \mu \mathrm{g} / \mathrm{l}$ ) with respect to baseline (average value $10.7 \mu \mathrm{g} / \mathrm{l}$ ), while that of 4-hydroxybenzoic acid increased from an average baseline value of $8.6 \mu \mathrm{g} / 1$ to an average value of $18.0 \mu \mathrm{g} / \mathrm{l}$ in WG and WB.

Fig. 3 shows the concentrations of faecal SCFA. No significant changes in faecal concentrations of acetic, propionic, butyric or caproic acid were observed over the course of the trial, neither between pre-WG and $\mathrm{WG}$ and pre-WB and WB nor when placebo (WB) and treatment (WG) were compared.

\section{Biomarkers of gut health}

Table 3 summarises data on digestive tolerance and stool consistency, as recorded by the volunteers during intake of the breakfast cereals. Stool frequency was higher during ingestion of WB compared with WG $(P<0.05)$. Stool consistency, qualitatively graded by volunteers as hard, formed, or soft, varied greatly between individuals. A greater proportion of stools described as formed were reported during WG ingestion, while there was an increase in soft stools $(P<0 \cdot 001)$ and in flatulence upon ingestion of WB $(P<0.001)$.

The severity and frequency of reported changes in digestive tolerance varied greatly between volunteers, with neither treatment resulting in adverse symptomology.

\section{Faecal water genotoxicity}

Faecal water genotoxicity varied greatly between volunteers at the beginning of the study ranging from $6.3 \%$ tail intensity to $66.1 \%$ tail intensity (CV $74.4 \%$ ). Neither WG nor WB significantly influenced the potential of faecal water to induce strand breaks (Fig. 4). However, for the quartile of volunteers who had the highest genotoxic activity at baseline (genotoxicity $\geq 24.6 \%$ tail intensity) there was a reduction in the faecal water genotoxicity after intervention with cereals, but this decrease was not significant (baseline, 42.90 (SD 16.68) \%; WG, 28.39 (SD 16.88) \% and WB, 24.35 (SD 16.56) \% tail intensity, mean (SD), $n 8$, one-way ANONA, $P=0.0884)$. 

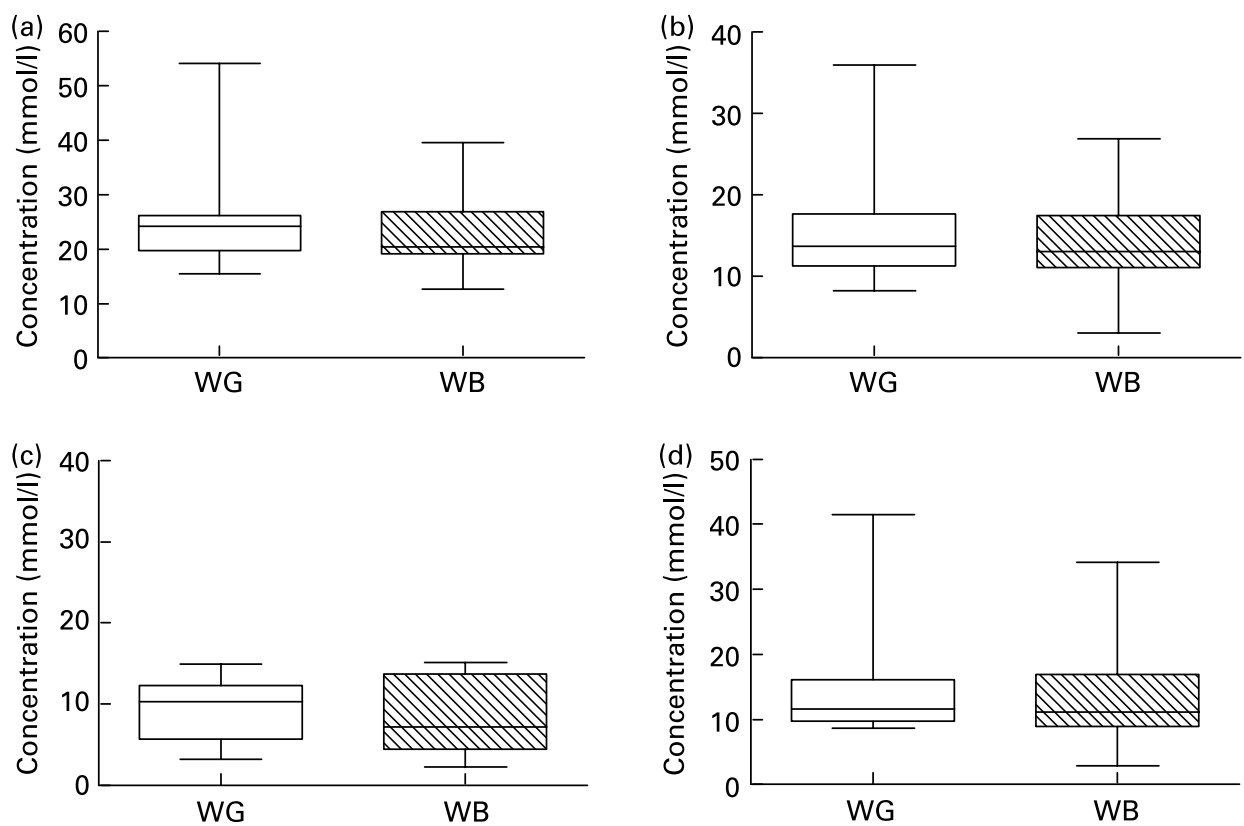

Fig. 3. SCFA concentrations in faecal samples collected from volunteers over the course of the trial measured by gas-chromatography. (a) Acetic acid; (b) Butyric acid; (c) Caproic acid; (d) propionic acid. Data are depicted as box plots with maximum value, 75th percentile (upper line of box), median (middle line of box), 25th percentile (lower line of box) and minimum ( $n 31)$.

$n$ 8, one-way ANOVA, $P=0 \cdot 0884)$. There was no difference between cereal treatments.

\section{Blood lipid parameters}

Fig. 5 shows data for TC, HDL-cholesterol, glucose and insulin, and NEFA measured in blood samples taken at baseline and following ingestion of WB and WG. Ingestion of neither breakfast cereal impacted upon blood lipid/metabolic parameters during the relatively short 3-week feeding period. No significant differences were observed in these parameters between WG and WB feeding periods. When the effect of the breakfast cereals was examined in those volunteers presenting with the highest starting TC concentrations (the top quartile of TC), a significant reduction in TC was observed from a baseline concentration of 5.576 (SD $0.421) \mathrm{mm}$, to 4.216 (SD 1.006) $\mathrm{mm}$ after WG ingestion and 4.385 (SD 1.093) $\mathrm{mM}$, after $\mathrm{WB}$ ingestion ( $n$ 8, one-way ANOVA, $P<0.05)$.

\section{Discussion}

A prebiotic is defined as 'a selectively fermented ingredient that allows specific changes, both in the composition and/or

Table 3. Summary of bowel habit and gastrointestinal symptom data recorded by thirty-one volunteers over course of the trial. The percentage coverage of each category over the total number of responses given per volunteer was determined.

(Mean values and standard deviations)

\begin{tabular}{|c|c|c|c|c|c|c|c|c|}
\hline & \multicolumn{2}{|c|}{ Stool frequency } & \multicolumn{2}{|c|}{ Hard } & \multicolumn{2}{|c|}{ Formed } & \multicolumn{2}{|c|}{ Soft } \\
\hline & Mean & $\mathrm{SD}$ & Mean & SD & Mean & $\mathrm{SD}$ & Mean & SD \\
\hline \multicolumn{9}{|c|}{ Stool consistency } \\
\hline WB & $37.84^{*}$ & 3.22 & 0.6 & 1.09 & $14 \cdot 4$ & $7 \cdot 0$ & $6.5 \dagger$ & $7 \cdot 2$ \\
\hline \multirow[t]{2}{*}{ WG } & $26 \cdot 97$ & 1.72 & 0.7 & $1 \cdot 3$ & $17 \cdot 1$ & $5 \cdot 6$ & $3 \cdot 3$ & $5 \cdot 7$ \\
\hline & \multicolumn{2}{|c|}{ None } & \multicolumn{2}{|c|}{ Mild } & \multicolumn{2}{|c|}{ Moderate } & Severe & \\
\hline \multicolumn{9}{|c|}{ Abdominal Pain } \\
\hline WB & $12 \cdot 7$ & 8.9 & $5 \cdot 1$ & $6 \cdot 7$ & $2 \cdot 4$ & $5 \cdot 8$ & 0.3 & 1.4 \\
\hline WG & $11 \cdot 6$ & $9 \cdot 3$ & $8 \cdot 2$ & 8.9 & $1 \cdot 3$ & 3.9 & 0.06 & 0.35 \\
\hline \multicolumn{9}{|c|}{ Stomach or Intestinal bloating } \\
\hline WB & 8.9 & 9.0 & 9.0 & 8.54 & $1 \cdot 25$ & 3.9 & 0.48 & $2 \cdot 7$ \\
\hline WG & $10 \cdot 3$ & 1.0 & 9.6 & 9.8 & $1 \cdot 16$ & 4.0 & 0.9 & $2 \cdot 4$ \\
\hline \multicolumn{9}{|c|}{ Flatulence } \\
\hline WB & 3.6 & $6 \cdot 6$ & 6.4 & $7 \cdot 7$ & $7 \cdot 3$ & 9.2 & $2 \cdot 70 \ddagger$ & 6.07 \\
\hline WG & 9.4 & 9.5 & 8.5 & 9.0 & 1.7 & 4.8 & 0.1 & 0.7 \\
\hline
\end{tabular}

* Stool frequency was higher during ingestion of WB compared with WG $(P<0.05, P$ value from Tukey's post test). †An increase in soft stools during WB intake $(P<0.001)$.

$\ddagger$ The severity and frequency of reported changes in digestive tolerance varied greatly between volunteers, with neither treatment resulting in adverse symptomology. However, there was an increase of flatulence upon ingestion of WB $(P<0.001) .11851$ Costabile Queries to author 


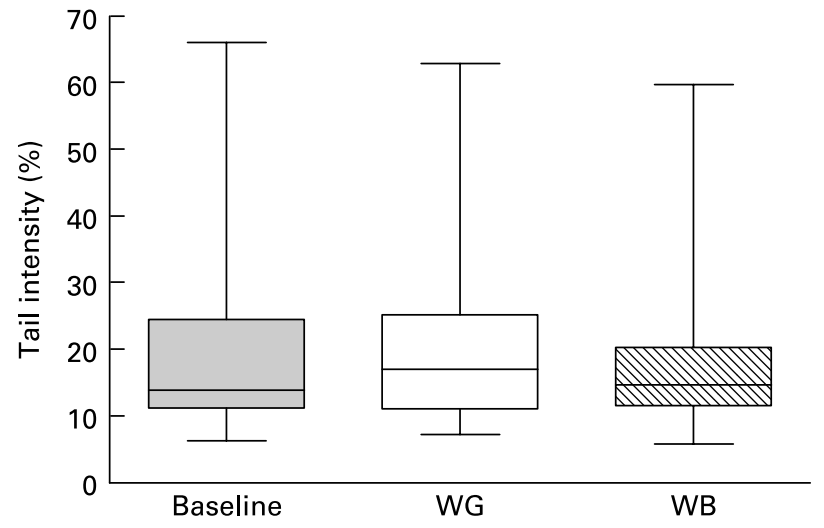

Fig. 4. Faecal water genotoxicity as measured by single cell gel electrophoresis. No significant difference in DNA strand breaks measured as percentage of tail intensity was observed upon ingestion of whole-grain (WG) or wheat bran (WB) breakfast cereals. Data are depicted as box plots with maximum value, 75th percentile (upper line of box), median (middle line of box), 25th percentile (lower line of box) and minimum ( $n 31)$.

activity in the gastrointestinal microbiota that confers benefits upon host well-being and health ${ }^{27}$. There is a growing body of evidence supporting the beneficial health effects of prebiotics on bowel habit and constipation ${ }^{28-32}$ and increased mineral absorption ${ }^{33-36}$ and recently, in reducing the risk for some chronic diseases (e.g. colon cancer and CVD). Prebiotics may have chemopreventive effects in colorectal cancer as it was shown that prebiotics prevented the occurrence of preneoplastic lesions and tumours in chemically-induced colon carcinogenesis in rodent models ${ }^{1}$. Recently, intervention with oligofructose-enriched inulin in combination with probiotics in human subjects favourably altered colon cancer biomarkers in high-risk individuals (polypectomised patients $)^{37}$. It was also reported that consumption of prebiotics lowered TC and TAG in plasma ${ }^{32,38-40}$ suggesting beneficial effects especially in hyperlipidaemic individuals who have an increased risk for CVD and type II diabetes ${ }^{41}$.

Likewise, epidemiological studies showed an inverse association between intake of whole grains and the risk of several chronic diseases including CVD, type II diabetes and cancer $^{3}$. As whole grains contain considerable amounts of fermentable carbohydrates it was proposed that one mechanism for the observed protection offered by whole grains is their impact on the gut microbiota ${ }^{4}$. However, evidence to support the hypothesis that whole grains can influence bacterial populations and their activities in the gut is lacking.

To test this hypothesis, we measured the impact of WG wheat compared with $\mathrm{WB}$ on the human gut microbiota. The primary objective was to identify differences in the relative population levels of intestinal bacteria and their metabolic activities upon ingestion of WG compared with WB breakfast cereal. A secondary objective was to assess possible health effects by measuring biomarkers of gut health (bowel habit and faecal water genotoxicity) and CVD (blood lipid parameters). In particular the concentration of ferulic acid, $95 \%$ of which is bound to the arabinoxylan present in the bran fraction of the wheat kernel and can be released or transformed by microbiota action, was determined.

The choice of this WG breakfast cereal was made following preliminary in vitro screening of three WG breakfast cereals compared with WB. In this screening, the WG breakfast cereal selected performed better than the others in terms of bifidogenicity and changes in SCFA production with increased concentrations of butyrate (data not shown).

Using direct molecular based enumeration of faecal bacteria, we have shown in this study that ingestion of a WG breakfast cereal results in significantly higher numbers of $B i$ fidobacterium spp. in stool samples compared with an equivalent quantity of the WB based breakfast cereal after a $21-\mathrm{d}$ feeding period. Although numbers of lactobacilli increased upon consumption of both breakfast cereals, there were
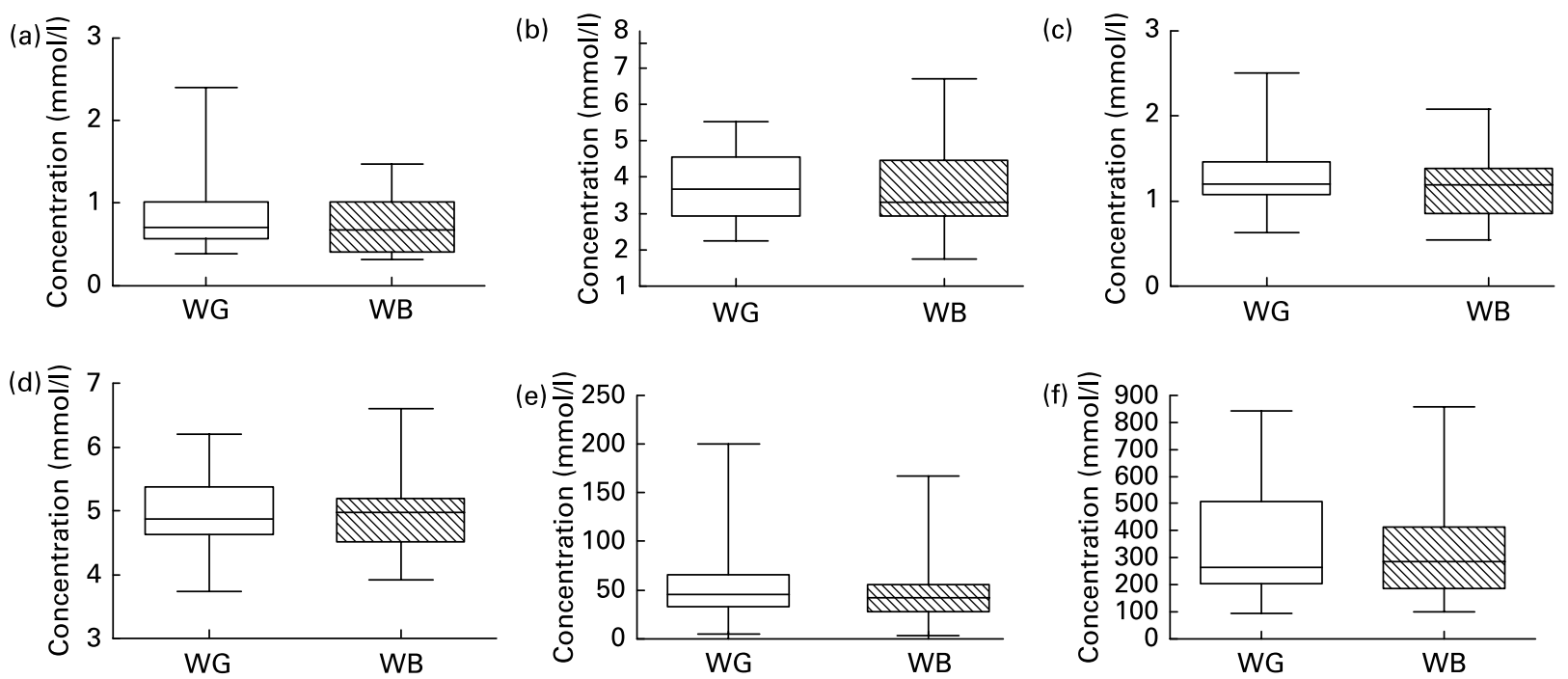

Fig. 5. (a) TAG, (b) total cholesterol, (c) HDL-cholesterol, (d) blood glucose, (e) insulin and (f) NEFA concentrations determined in fasting blood samples collected from each volunteer at baseline before ingestion of test breakfast cereals, after the 21-d intervention with whole-grain (WG) or wheat bran (WB) breakfast cereals, and after the 14-d post-WB and post-WG wash-out periods. No significant differences were observed upon ingestion of WG or WB breakfast cereals. Data are depicted as box plots with maximum value, 75th percentile (upper line of box), median (middle line of box), 25th percentile (lower line of box) and minimum ( $n$ 31). 
significantly higher numbers of lactobacilli upon ingestion of WG compared with WB. It cannot be determined whether the increase in clostridia after WB intake should be seen as detrimental as the applied probe also recognises commensal bacteria such as Clostridium butyricum and Clostridium beijerinckii ${ }^{22}$. That WB is indeed an energy source for clostridia has been observed by Leitch et al. ${ }^{42}$ who showed that mainly unknown bacteria belonging to clostridia cluster XIVa selectively colonise WB. The different effects of WG and WB cereals on gut microbiota may be due to the different composition, as WG contained a considerably higher content of non-sugar carbohydrates, which might represent fermentable carbohydrates. This is the first report that consumption of a whole plant food, which has undergone little processing, may act as a prebiotic. However, there were no differences in faecal SCFA after ingestion of WG cereals. This is not surprising as SCFA are readily absorbed in the large intestine. Thus, an increase in acetic and butyric acid was only observed in colostomy effluent after intervention with a high concentration of resistant starch in human subjects ${ }^{43}$, while other human intervention studies with proven prebiotics failed to show changes in the fermentation profile in faeces ${ }^{44-48}$. Similarly, an increase of SCFA after prebiotic intervention in rats was mainly observed in the caecum, but not in faeces ${ }^{49,50}$.

A significant increase of the ferulic acid plasma concentrations was observed upon ingestion of both WG and WB, without significant differences between the two types of breakfast cereals. It should be noted that this increase was observed in the plasma of fasting subjects. This indicates that the rapid absorption from the upper gut, of the small fraction of free ferulic acid present in cereal fraction is followed by colonic absorption of ferulic acid released through microbiotal metabolism. The concentration of ferulic acid found in the subjects is in agreement with those reported in the studies by Kern et al. ${ }^{51}$ who measured the bioavailability of ferulic acid after a single dose of WG breakfast cereal.

The fact that a regular consumption of WG tripled the ferulic acid concentration in fasting plasma may be of physiological relevance ${ }^{52}$. In fact, food phenolic compounds in plasma are usually detected for a limited window-time of $0.5-3 \mathrm{~h}$ after the consumption of fruit or other free-phenolic-rich food such as coffee ${ }^{17,24,53-55}$. Our data extend the results of the studies by Rondini et al. ${ }^{56,57}$ who showed that in rats plasma ferulic acid concentration is constant up to $24 \mathrm{~h}$ after bran consumption. Therefore our finding demonstrates for the first time that in human subjects the regular consumption of WG and WB is followed by a slow and continuous release of phenolic acids into the bloodstream. The continuous presence of these antioxidants could efficiently preserve some oxidation targets such as LDL and TAG thus contributing to the well known association between WG consumption and prevention of CVD.

A secondary objective of this study was to assess the relative impact of WG and WB breakfast cereals on health effects by measuring changes in bowel habit or symptomology and faecal water genotoxicity, blood lipid and metabolic profiles, specifically, blood TAG, TC, HDL-cholesterol, NEFA, glucose and insulin concentrations. An improvement in bowel habit was observed upon ingestion of both breakfast cereals, with WB increasing stool frequency (without diarrhoea), while WG stool form was more commonly described as formed than WB stools and flatulence was recorded as less severe during WG ingestion. Although there was a trend towards reduced faecal water genotoxicity upon ingestion of both breakfast cereals in volunteers with high faecal water genotoxicity before intervention, this effect was not significant. Taking all volunteers into account there was no difference in faecal water genotoxicity after intervention due to high inter-individual variation. Similar high inter-individual variation in faecal water genotoxicity was reported from other human studies ${ }^{58-62}$ making it difficult to observe an intervention effect in a small study population ${ }^{61}$. Further studies with greater numbers of volunteers are warranted to fully establish the impact of WG cereals or prebiotics on faecal water genotoxicity, especially in individuals with high faecal water genotoxicity who may be at a heightened risk of developing colon cancer. It is not altogether surprising, that there are no obvious differences considering the similarities in the test foods (many of the complex polyphenolic compounds present in WB are also present in WG wheat, including those likely to lead to the formation of signature phenolic derivatives, such as ferulic acid, often used as biomarkers of cereal grain ingestion) and the fact the volunteers were on an open diet, the only restriction being on consumption of other breakfast cereals, probiotics or commercial prebiotic functional foods.

Similarly, no significant differences in blood lipid or metabolic (glucose or insulin) parameters were observed. This too is not surprising for a short-term feeding study in healthy individuals and longer-term trials in high-risk populations are warranted to investigate the efficacy of WG and WB breakfast cereals in impacting on biomarkers of CVD. However, when the effect of breakfast cereal ingestion was examined in those within the top quartile for total serum cholesterol, a significant reduction in TC was observed for both breakfast cereals, with WG apparently having slightly greater cholesterol-lowering effect. No significant change in serum HDLcholesterol was observed for these individuals during cereal intake, indicating that this reduction on TC may be viewed as beneficial in terms of CVD risk. Although the mean TC (5.576 (SD 0.421) $\mathrm{mm}$ ) of this top quartile was still within the normolipidaemic range, these findings do suggest that intake of either breakfast cereal may have a beneficial impact on blood lipid profiles. So far, significant decreases in blood lipids after ingestion of prebiotics have usually only been observed in hyperlipidaemic individuals ${ }^{32,38-40}$ while studies in the normolipidaemic failed to show a reduction ${ }^{28,48,63-65}$. Another study with healthy volunteers which reported a lowering effect on TAG after intervention with inulin chose subjects with moderately raised TC and TAG levels ${ }^{66}$. These subjects would correspond to the volunteers in the upper quartile in this study supporting the beneficial effect observed here in this sub-group. In order to prove a beneficial effect of WG further studies involving larger numbers of individuals over a longer intervention period would be a prerequisite, especially in those with hyperlipidemia.

In conclusion, this study has, for the first time, demonstrated the differential impact of WG wheat and WB on the microbial ecology of the human gut. Additionally, it has established a prebiotic mode of activity for the WG breakfast cereal investigated with increased populations of bifidobacteria and lactobacilli compared to starting levels and the WB. Finally, the 
increase of the ferulic acid concentration in fasting plasma suggests that the WG intake caused a continuous release of antioxidant in the bloodstream. This study has established a prebiotic mode of action for a WG cereal, which together with antioxidant activities may contribute to the underlying mechanisms of protective health effects of WG wheat.

\section{Acknowledgements}

The authors thank Dr Julie Lovegrove, Dr Kim Jackson and Ms Jan Luff of the Hugh Sinclair Clinical Unit, Department of Food Biosciences, The University of Reading for use of their facility and their help with the study, and visiting students Elodie Duclos and Nicolas Pion, for technical assistance.

\section{References}

1. Jacobs DR Jr, Marquart L, Slavin J \& Kushi LH (1998) Wholegrain intake and cancer: an expanded review and meta-analysis. Nutr Cancer 30, 85-96.

2. Anderson JW, Hanna TJ, Peng X \& Kryscio RJ (2000) Whole grain foods and heart disease risk. J Am Coll Nutr 19, 291S-299S

3. Kushi LH, Meyer KA \& Jacobs DR Jr (1999) Cereals, legumes, and chronic disease risk reduction: evidence from epidemiologic studies. Am J Clin Nutr 3, 451S-458S.

4. Slavin J (2003) Why whole grains are protective: biological mechanisms. Proc Nutr Soc 62, 129-134.

5. Rastall RA, Gibson GR, Gill HS, Guarner F, Klaenhammer TR, Pot B, Reid G, Rowland IR \& Sanders ME (2005) Modulation of the microbial ecology of the human colon by probiotics, prebiotics and synbiotics to enhance human health: an overview of enabling science and potential applications. FEMS 52, $145-152$.

6. Fava F, Gitau R, Lovegrove J \& Tuohy KM (2006) The gut microflora and lipid metabolism: implications for human health. Curr Med Chem 13, 3005-3021.

7. Cummings JH, Antoine JM, Azpiroz F, et al. (2004) PASSCLAIM-gut health and immunity. Eur $J$ Nutr 43, II118-II173.

8. Rakoff-Nahoum S, Paglino J, Eslami-Varzaneh F, Edberg S \& Medzhitov R (2004) Recognition of commensal microflora by toll-like receptors is required for intestinal homeostasis. Cell 118, 229-241.

9. Gibson GR \& Roberfroid MB (1995) Dietary modulation of the human colonic microbiota: introducing the concept of prebiotics. J Nutr 125, 1401-1412.

10. Abrams SA, Griffin IJ, Hawthorne KM, Liang L, Gunn SK, Darlington G \& Ellis KJ (2005) A combination of prebiotic shortand long-chain inulin-type fructans enhances calcium absorption and bone mineralization in young adolescents. Am J Clin Nutr 82, 471-476.

11. Williams CM \& Jackson KG (2002) Inulin and oligofructose: effects on lipid metabolism from human studies. Br J Nutr 87, S261-S264

12. Burns AJ \& Rowland IR (2004) Antigenotoxicity of probiotics and prebiotics on faecal water-induced DNA damage in human colon adenocarcinoma cells. Mutat Res 551, 233-243.

13. Klinder A, Förster A, Caderni G, Femia AP \& Pool-Zobel BL (2004) Faecal water genotoxicity is predictive of tumor preventive activities by inulin-like oligofructoses, probiotics (Lactobacillus rhamnosus and Bifidobacterium lactis) and their synbiotic combination. Nutr Cancer 49, 144-155.
14. Pool-Zobel BL (2005) Inulin-type fructans and reduction in colon cancer risk: review of experimental and human data. Br J Nutr 93, S73-S90.

15. Esposito F, Arlotti G, Napolitano A, Vitale D \& Fogliano V (2005) Durum wheat bran by-products: a novel functional ingredients. Food Res Int 38, 1167-1173.

16. Wong JM, de Souza R, Kendall CW, Emam A \& Jenkins DJ (2006) Colonic health: fermentation and short chain fatty acids. J Clin Gastroenterol 40, 235-243.

17. Scalbert A, Morand C, Manach C \& Remesy C (2002) Absorption and metabolism of polyphenols in the gut and impact on health. Biomed Pharmacother 56, 276-282.

18. Tuohy KM, Kolida S, Lustenberger AM \& Gibson GR (2001) The prebiotic effects of biscuits containing partially hydrolysed guar gum and fructo-oligosaccharides - a human volunteer study. Br J Nutr 86, 341-348.

19. Harmsen HJM, Wildeboer-Veloo ACM, Grijpstra J, Knol J, Degener JE \& Welling GW (2000) Development of $16 \mathrm{~S}$ rRNA-based probes for the Coriobacterium group and the Atopobium cluster and their application for enumeration of Coriobacteriaceae in human faeces from volunteers of different age groups. Appl Environ Microbiol 66, 4523-4527.

20. Manz W, Amann R, Ludwig W, Vancanneyt M \& Schleifer KH (1996) Application of a suite of 16S rRNA-specific oligonucleotide probes designed to investigate bacteria of the phylum cytophaga-flavobacter-bacteroides in the natural environment. Microbiol 142, 1097-1106.

21. Langendijk PS, Schut F, Jansen GJ, Raangs GC, Kamphuis GR, Wilkinson MH \& Welling GW (1995) Quantitative fluorescence in situ hybridization of Bifidobacterium spp. with genus-specific 16S rRNA-targeted probes and its application in faecal samples. Appl Environ Microbiol 61, 3069-3075.

22. Franks AH, Harmsen HJM, Raangs GC, Jansen GJ, Schut F \& Welling GW (1998) Variations of bacterial populations in human faeces measured by fluorescence in situ hybridization with group-specific 16S rRNA-targeted oligonucleotide probes. Appl Environ Microbiol 64, 3336-3345.

23. Harmsen HJM, Elfferich P, Schut F \& Welling GW (1999) A 16S rRNA-targeted probe for detection of lactobacilli and enterococci in faecal samples by fluorescence in situ hybridization. Microb Ecol Health Dis 11, 3-12.

24. Kroon PA, Faulds CB, Ryden P, Robertson JA, Williamson G \& Garcia-Conesa MT (1997) Release of covalently bound of ferulic acid from fibre in the human colon. J Agric Food Chem 45, 661-667.

25. Singh NP, McCoy MT, Tice RR \& Schneider EL (1988) A simple technique for quantitation of low levels of DNA damage in individual cells. Exp Cell Res 175, 184-191.

26. Pool-Zobel BL, Bub A, Müller H, Wollowski I \& Rechkemmer $G$ (1997) Consumption of vegetables reduces genetic damage in humans: first results of an intervention trial with carotenoid-rich foods. Carcinogenesis 18, 1847-1850.

27. Gibson GR, Probert HM, Van Loo J, Rastall RA \& Roberfroid MB (2004) Dietary modulation of the human colonic microbiota: updating the concept of prebiotics. Nutr Res Rev 17, 259-275.

28. Chen HL, Lu YH, Lin JJ \& Ko LY (2001) Effects of isomaltooligosaccharides on bowel functions and indicators of nutritional status in constipated elderly men. J Am Coll Nutr 20(1), 44-49.

29. Den Hond E, Geypens B \& Ghoos Y (2000) Effect of high performance chicory inulin on constipation. Nutr Res 20, 731-736.

30. Gibson GR, Beatty ER, Wang X \& Cummings JH (1995) Selective stimulation of bifidobacteria in the human colon by oligofructose and inulin. Gastroenterology 108, 975-982.

31. Kleessen B, Sykura B, Zunft HJ \& Blaut M (1997) Effects of inulin and lactose on fecal microflora, microbial activity, and 
bowel habit in elderly constipated persons. Am J Cli Nutr $\mathbf{6 5}$, 1397-1402.

32. Wang HF, Lim PS, Kao MD, Chan EC, Lin LC \& Wang NP (2001) Use of isomalto-oligosaccharide in the treatment of lipid profiles and constipation in hemodialysis patients. Ren Nutr 11, 73-79.

33. Coudray C, Bellanger J, Castiglia-Delavaud C, Remesy C, Vermorel M \& Rayssignuier Y (1997) Effect of soluble or partly soluble dietary fibres supplementation on absorption and balance of calcium, magnesium, iron, and zinc in healthy young men. Eur J Clin Nutr 51, 375-380.

34. Griffin IJ, Davila PM \& Abrams SA (2002) Non-digestible oligosaccharides and calcium absorption in girls with adequate calcium intakes. Br J Nutr 87, S187-S191.

35. Van den Heuvel EGH, Muys T, Van Dokkum W \& Schaafsma G (1997) Lactulose stimulates calcium absorption in postmenopausal women. J Bone Miner Res 7, 1211-1216.

36. Van den Heuvel EGH, Muys T, Van Dokkum W \& Schaafsma G (1999) Oligofructose stimulates calcium absorption in adolescents. Am J Clin Nutr 69, 544-548.

37. Rafter J, Bennett M, Caderni G, et al. (2007) Dietary synbiotics reduce cancer risk factors in polypectomized and colon cancer patients. Am J Clin Nutr 85, 488-496.

38. Hidaka H, Tashiro Y \& Eida T (1991) Proliferation of bifidobacteria by oligosaccharides and their useful effect on human health. Bifid Microflora 10, 65-79.

39. Davidson MH, Synecki C, Maki KC \& Drennan KB (1998) Effects of dietary inulin in serum lipids in men and women with hypercholesterolemia. Nutr Res 3, 503-517.

40. Causey JL, Feirtag JM, Gallaher DD, Tungland BC \& Slavin JL (2000) Effects of dietary inulin on serum lipids, blood glucose and the gastrointestinal environment in hypercholesterolemic men. Nutr Res 20, 191-201.

41. Shaw DI, Hall WL \& Williams CM (2005) Metabolic syndrome: what is it and what are the implications? Proc Nutr Soc 64(3), 349-357.

42. Leitch EC, Walker AW, Duncan SH, Holtrop G \& Flint HJ (2007) Selective colonization of insoluble substrates by human faecal bacteria. Environ Microbiol 9, 667-679.

43. Ahmed R, Segal I \& Hassan H (2000) Fermentation of dietary starch in humans. Am J Gastroenterology 95, 1017-1020.

44. Alles MS, Hartemink R, Meyboom S, Harryvan JL, Van Laere KMJ, Nagengast FM \& Hautvast JGAJ (1999) Effects of transgalactooligosaccharides on the composition of the human intestinal microflora and on putative risk markers for colon cancer. Am J Clin Nutr 69, 980-991.

45. Bouhnik Y, Neut C, Raskine L, Michel C, Riottot M, Andrieux C, Guillemot F, Dyard F \& Flourie B (2004) Prospective, randomized, parallel-group trial to evaluate the effects of lactulose and polyethylene glycol-4000 on colonic flora in chronic idiopathic constipation. Alimentary Pharm \& Therapeutics 19, 889-899.

46. Brighenti F, Casiraghi MC, Canzi E \& Ferrari A (1999) Effect of consumption of a ready-to-eat breakfast cereal containing inulin on the intestinal milieu and blood lipids in healthy male volunteers. Eur J Clin Nutr 53, 726-733.

47. Hylla S, Gostner A, Dusel G, Anger H, Batram H-P, Christl SU, Kasper H \& Scheppach W (1998) Effects of resistant starch on the colon in healthy volunteers: possible implications for cancer prevention. Am J Clin Nutr 67, 136-142.

48. Kruse H-P, Kleessen B \& Blaut M (1999) Effects of inulin on faecal bifidobacteria in human subjects. Br J Nutr 82, 375-382.

49. Campbell JM, Fahey GC \& Wolf BW (1997) Selected indigestible oligosaccharides affect large bowel mass, cecal and faecal short-chain fatty acids, $\mathrm{pH}$ and microflora in rats. $J$ Nutr $\mathbf{1 2 7}$, 130-136.
50. Kleessen B, Stoof G, Proll J, Schmiedl D, Noack J \& Blaut M (1997) Feeding resistant starch affects faecal and caecal microflora and short-chain fatty acids in rats. J Anim Sci $\mathbf{7 5}$, $2453-2462$.

51. Kern SM, Bennett RN, Mellon FA, Kroon PA \& Garcia-Conesa MT (2003) Absorption of hydroxycinnamates in humans after high-bran cereal consumption. J Agric Food Chem 51, 6050-6055.

52. Andreasen MF, Landbo AK, Christensen LP, Hansen A \& Meyer AS (2001) Antioxidant effects of phenolic rye (Secale cereale $L$.) extracts, monomeric hydroxycinnamates, and ferulic acid dehydrodimers on human low-density lipoproteins. J Agric Food Chem 51, 4090-4096.

53. Scalbert A \& Williamson (2000) Dietary intake and bioavailabity of polyphenols. J Nutr 130, 2073S-2085S.

54. Natella F, Belelli F, Gentili V, Ursini F \& Scaccini C (2002) Grape seed proanthocyanidins prevent plasma postprandial oxidative stress in humans. J Agric Food Chem 50, 7720-7725.

55. Cremin P, Kasim-Karakas S \& Waterhouse AL (2001) LC/ESMS detection of hydroxycinnamates in human plasma and urine. J Agric Food Chem 49, 1747-1750.

56. Rondini L, Peyrat-Maillard MN, Marsset-Bagliéri A \& Berset C (2002) Sulfated ferulic acid is the main in vivo metabolite found after short-term ingestion of free ferulic acid in rats. J Agric Food Chem 50, 3037-3041.

57. Rondini L, Peyrat-Maillard MN, Marsset-Baglieri A, Fromentin G, Durand P, Tomé D, Prost M \& Berset C (2004) Bound ferulic acid from bran is more bioavailable than the free compound in rat. J Agric Food Chem 52, 4338-4343.

58. Osswald K, Becker TW, Grimm M, Jahreis G \& Pool-Zobel BL (2000) Inter- and intra-individual variation of faecal water genotoxicity in human colon cells. Mut Res 472, 59-70.

59. Venturi M, Hambly RJ, Glinghammar B, Rafter JJ \& Rowland IR (1997) Genotoxic activity in human faecal water and the role of bile acids: a study using the alkaline comet assay. Carcinogenesis 18, 2353-2359.

60. Woods JA, Dunne C, Collins JK, Shanahan F \& O'Brien NM (2002) Genotoxicity of fecal water in a free-living Irish population. Nutr Cancer 42(1), 62-69.

61. Cross AJ, Greetham HL, Pollock JR, Rowland IR \& Bingham SA (2006) Variability in fecal water genotoxicity, determined using the Comet assay, is independent of endogenous $\mathrm{N}$-nitroso compound formation attributed to red meat consumption. Environ Mol Mutagen 47(3), 179-184.

62. Klinder A, Karlsson PC, Clune Y, Hughes R, Glei M, Rafter J, Rowland IR, Collins JK \& Pool-Zobel BL (2007) Faecal water as a non-invasive biomarker in nutritional intervention: comparison of preparation methods and refinements of different endpoints. Accepted for publication in Nutr Cancer 57(2), 158-167.

63. Luo J, Rizkalla SW, Alamowitch C, et al. (1996) Chronic consumption of short-chain fructooligosaccharides by healthy subjects decreased basal hepatic glucose production but had no effect on insulin stimulated glucose mechanism. Am J Clin Nutr 63, 939-945.

64. Pedersen A, Sandström B \& Van Amelsvoort JMM (1997) The effect of ingestion of inulin on blood lipids and gastrointestinal symptoms in healthy females. Br J Nutr 78, 215-222.

65. Alles MS, De Roos NM, Bakz JC, Van de Lisdonk E, Zock PL \& Hautvast JGAJ (1999) Consumption of fructo-oligosaccharides does not favorably affect blood glucose and serum lipid concentrations in patients with type 2 diabetes. Am J Clin Nutr 69, 64-69.

66. Jackson KG, Taylor GRJ, Clohessy AM \& Williams CM (1998) The effect of the daily intake of inulin on fasting lipid, insulin and glucose concentrations in middle-aged men and women. Br J Nutr 82, 23-30. 